\title{
Estudos sobre currículo de enfermagem na educação profissional
}

\section{Studies on nursing curriculum in professional education}

\author{
Shirley da Rocha Afonso \\ Orcid: https://orcid.org/0000-0003-1824-0451 \\ Centro Estadual de Educação Tecnológica Paula Souza, São Paulo, Brasil, \\ shirley.afonso@cps.sp.gov.br \\ Maria Lucia Mendes de Carvalho \\ Orcid: https://orcid.org./0000-0002-5452-3785 \\ Centro Estadual de Educação Tecnológica Paula Souza, São Paulo, Brasil, \\ maria.mendes@cps.sp.gov.br
}

Received on 10/12/2020 - Approved on 14/12/2020

\begin{abstract}
Resumo
É importante promover a preservação dos registros da trajetória da educação de nível médio em enfermagem, pois, ainda são escassas as literaturas que tratam sobre a profissão técnica de enfermagem e sua evolução no país e na América Latina. Este estudo é do tipo bibliométrico, com objetivo de quantificar a produção científica a respeito dos currículos educacionais da formação de nível médio em enfermagem desde 1940. As publicações evidentes são encontradas nos anos de 2004, 2018 e 2019, concentrando os estudos nas instituições de língua espanhola e nas Escolas de Enfermagem da Universidade de São Paulo, tanto em São Paulo como em Ribeirão Preto. Tal concentração demonstra carência no desenvolvimento desses estudos em outras universidades e escolas de enfermagem.
\end{abstract}

Palavras-chave: História de Enfermagem. Educação em Enfermagem. Currículo.

\begin{abstract}
It is important to promote the preservation of the records of the trajectory of secondary education in nursing, as there is still a lack of literature on the technical profession on nursing and its evolution in the country and in Latin America. This study is of the bibliometric type, with the objective of quantifying the scientific production regarding the educational curricula of secondary education in nursing since 1940. The evident publications are found in the years 2004, 2018 and 2019, concentrating the studies in the institutions of Spanish language and at the Nursing Schools of the University of São Paulo, both in the cities of São Paulo and Ribeirão Preto. Such concentration demonstrates a lack in the development of these studies in other universities and nursing schools.
\end{abstract}

Keywords: Nursing History. Nursing Education. Curriculum. 
A educação de nível médio em enfermagem exige a elaboração de processos pedagógicos elementares e que sejam capazes de evidenciar e prevalecer 0 trabalho técnico-científico de referência.

Nessa perspectiva, a história pedagógica da formação técnica em enfermagem precisa ser valorizada, porque o profissional e a sociedade preservam e sustentam a autonomia profissional da Enfermagem de forma evidente.

Viñao (1998), destaca a história da disciplina como uma operação setorial na escola, expandindo os campos relativos à autonomia dos estudos na história do currículo educacional. Define as relações como uma atividade educativa, que insiste na relação do emprego entre o ser humano e o espaço escolar estabelecendo culturas organizacionais efetivas para a formação social e material do aluno.

Faz-se importante promover processos de preservação dos registros oficiais que contam a trajetória da educação de nível médio em enfermagem, pois, ainda é escassa as literaturas que tratam sobre a profissão técnica de enfermagem e sua evolução no país e na América Latina.

Há que se destacar, no processo de preservação da memória e história da educação profissional, o marco sobre a escolarização para o mercado do trabalho em saúde no país. As literaturas apontam, conforme Silva (2017), que este tipo de ofício iniciou no século XIX, a fim de subsidiar a mão-de-obra dos hospitais exercendo práticas de saúde reguladas e reconhecidas apenas em 1920, por meio da criação do Departamento Nacional de Saúde Pública.

O espaço escolar adiciona dificuldade para a integração e preservação da memória da história do currículo, principalmente sob o ponto de vista profissionalizante, pois, os registros e a regulamentação da educação profissional são condicionados a um processo administrativo muito burocrático e que atende apenas a uma formação por interesse (Viñao, 1998).

Com esse movimento de regulação da profissão em saúde, o exercício profissional de nível médio em enfermagem é regulamentado e autorizado, a partir da década de 1940 para atender as exigências do mercado de trabalho. Ganha notoriedade no processo de organização educacional, a partir de 1961, com a Lei de Diretrizes e Bases da Educação (Silva, 2017).

Todo processo de regulamentação e autorização da implementação na educação profissional formal repercute, então, conforme Silva (2017), sob a forma do processo de desenvolvimento do mercado de trabalho, tendo a presença de profissionais qualificados e, com isso, o avanço da tecnologia na área de saúde.

\footnotetext{
Todas essas questões podem ser referidas ao âmbito da escola como lugar, à sua configuração arquitetônica e à ordenação espacial de pessoas e objetos, de usos e funções que têm lugar em tal âmbito. Mas também já indicam alguns dos aspectos que fazem da escola um espaço peculiar e relevante. Em especial quando se tem em conta que nela se permanece durante aqueles anos em que se formam as estruturas mentais básicas das crianças, adolescentes e jovens. Estruturas mentais conformadas por um espaço que, como todos, socializa e educa, mas que, diferentemente de outros, situa e ordena com essa finalidade específica a tudo e a todos quantos nele se encontram (Vinão Frago, 2001: 64).
}

Vinão Frago (2006a), para a história da educação considera que os aspectos ou elementos mais visíveis no âmbito histórico-educativo da cultura escolar são: 
1) Los actores, es decir, los profesores, los padres, los alumnos y el personal de administración y servicios. A los primeiros les corresponde, por su especial posición, el papel más relevante en la conformación de la cultura escolar. De ahí la importância de conocer su formación, modos de selección, carrera acadêmica, categorias, estatus, associacionismo, composición social, por edades o sexos, ideas y representaciones mentales, entre otros aspectos, así como su grado de profesionalización em relación com unas matérias o disciplinas dadas; 2) Los discursos, linguajes, conceptos y modos de comunicación utilizados en el mundo acadêmico y escolar. O sea, el léxico o vocabulário, las fórmulas y pautas linguísticas, las expressiones y frases más utilizadas, las jergas, y el peso respectivo de lo oral, lo escrito, lo gestual y lo icônico en el aula, fuera de ella y en los modos de evaluación. El predomínio o no, social y cultural, de determinadas "categorias" o "conceptos institucionales" relativos a "características significativas de la escolarización y el curriculum" - la "extención de la conformidade" sobre los mismos -, será um elemento determinante de los câmbios organizativos y curriculares (Reid, 1998, p.8). De ahí el que cada reforma trate de imponer su própria jerga o vocabulário (Rodríguez Diéguez, 2001). Uma jerga que deberá ser aprendida y manejada en sus relaciones con la administración, y entre sí, por los profesores, los padres y los alumnos. 3) Los aspectos organizativos e institucionales. Dentro de ellos ofrecen uma especial relevância: a) las prácticas y rituales de la acción educativa: la graduación y classificación de los alumnos, la división del saber en disciplinas independientes y su jerarquia, la idea de la classe como un espacio-tiempo gestionado por um solo maestro, la distribuición y usos del espacio y del tempo, los critérios de evaluación y promoción de los alumnos, etc.; b) la marcha de la classe, es decir, los modos, a la vez disciplinarios e instructivos, de relación y comunicación didáctica en el aula entre profesores y alumnos y entre los alumnos; y c) los modos organizativos formales - dirección, claustro, secretaría, etc. - e informales - tratamiento, saludos, actitudes, grupos, prejuícios, formas de comunicación, etc. - de funcionar y relacionarse em el centro docente. [...] 4) La cultura material de la escuela: su entorno físico-material y objetos (espacios, edificados y no edificados, mobiliário, material didáctico y escolar, etc). (Vinão Frago, 2006a: 56-60)

O modelo progressivo e motivador para o avanço tecnológico do mercado de trabalho em saúde, representa em desafios para a educação profissional de nível médio em enfermagem exigindo estratégias pedagógicas práticas e capazes de organizar o processo de aprendizagem significativo e instrumentalizador para o mercado assistencial da saúde.

Assim, percebe-se que os registros históricos são promotores da formação profissional de nível médio em enfermagem, por meio das diretrizes curriculares, os projetos pedagógicos, as organizações curriculares etc. São documentos símbolos eficazes, que retratam a preocupação da sistematização por um desenvolvimento dos saberes técnicos e científicos inerentes ao mercado de trabalho em saúde. Por isso, eles precisam ser flexíveis, adaptáveis e coerentes às tecnologias no mercado de trabalho.

Os registros e seus processos de mudança e transformação são importantes para destacar a trajetória histórica das práticas pedagógicas, capazes de evidenciar o tipo de oferta de ensino esperado nas situações diárias no trabalho de cada época.

Ao longo desses últimos dez anos, de acordo com Silva (2017), o ensino profissional técnico brasileiro tem crescido exponencialmente e progressivamente e, por isso, é preciso considerar a organização curricular, em sua especificidade e itinerário formativo, para além do desenvolvimento dos aspectos simples de aprendizagem, incluindo a aquisição de novos conhecimentos baseados na observação da realidade atual (Wermelinger et. al., 2020).

Em outras palavras, os processos formadores precisam reunir requisitos de escolarização atrelados às exigências atuais do mercado de trabalho e do meio social profissional.

A ocupação do espaço, sua utilização, supõe sua constituição como lugar. O "salto qualitativo" que leva do espaço ao lugar é, pois, uma construção. O espaço se projeta ou se imagina; o lugar se constrói. Constrói-se "a partir do fluir da vida" e a partir do espaço

History of Education in Latin America - HistELA, v. 3, e23519, 2020, p. 3 de 9 
como suporte; o espaço, portanto, está sempre disponível e disposto para converter-se em lugar, para ser construído (Viñao Frago, 2001: 61).

Nesse sentido, de acordo com Wermelinger et. al. (2020), os currículos escolares devem representar as reais competências e aptidões da profissão em enfermagem, destinando seu itinerário à formação propedêutica e das técnicas de produção específicas.

O cenário de formação de nível médio em enfermagem, ao longo desses anos, demonstra a necessidade de valorizar o conhecimento científico, direcionando as características específicas do trabalho em saúde (Wermelinger et. al., 2020).

Diante do exposto, afirma-se que a formação profissional de nível médio em enfermagem reúne documentos oficiais suficientes para construir uma trajetória educacional significativa para o trabalho em saúde. E por isso, só são necessários organizar os processos de preservação dos registros históricos.

Assim, busca-se identificar quais literaturas abordam a formação profissional de nível médio em enfermagem, destacando os aspectos curriculares educacionais (Afonso \& Neves, 2018), e, com isso, se define como objetivos identificar, descrever e classificar quais são as produções científicas que abordam os currículos de ensino médio em enfermagem, desde 1940.

Este estudo é do tipo bibliométrico, com objetivo de quantificar a produção científica a respeito dos currículos educacionais da formação de nível médio em enfermagem. Buscou-se reunir as informações a respeito do ano de publicação, os autores responsáveis, o vínculo institucional e localização geográfica, veículo de publicação, metodologia aplicada no estudo e descritores de indexação.

A coleta de dados foi realizada na Biblioteca Virtual em Saúde, nas bases de dados Medline, Lilacs, Bdenf - enfermagem, Ibecs, Cumed, Repositório RHS, Paho, Hisa - história da saúde, BBO - odontologia, Paho-IRIS e Coleciona- SUS, com os descritores "História de Enfermagem", "Educação em Enfermagem" e "Currículo", sem restrição de tempo, nos meses de agosto e setembro de 2020.

Foram selecionados apenas os artigos com acesso completo ao texto da íntegra e, após a leitura dos resumos encontrados, foi aplicado, como critério de inclusão, no resumo do artigo, referir-se à história da formação de nível médio em enfermagem, nacionais e internacionais que abordavam a trajetória do currículo de ensino dessa categoria de formação. Foram excluídos os artigos que, mesmo tendo os descritores buscados abordavam técnicas de desenvolvimento da assistência de enfermagem, ações práticas dos profissionais e a história de pessoas.

Os dados selecionados e indicados para análise deste estudo foram organizados em uma planilha Excel, relacionando os campos conforme as variáveis apontadas.

\section{Resultados e discussões}

Foram encontradas 2.125 referências nas bases de dados da Biblioteca Virtual em Saúde, destas foram identificados 761 estudos completos nas bases de dados Medline, LILACS, BDENF, IBECS, CUMED, Repositório RHS, PAHO, HISA, BBO, PAHO-IRIS e Coleciona-SUS.

Após a leitura superficial dos resumos foram identificados 16 estudos, que atendam aos critérios de estudo, sendo quatro artigos em PAHO, dois artigos em CUMED, cinco artigos em IBECS, quatro artigos em BEDENF e uma tese em LILACS, (Tabela1). 
Tabela 1: Relação de publicações, segundo periódico, título e ano. São Paulo, 2020.

\begin{tabular}{|c|c|c|}
\hline Periódico & Título do artigo & Ano \\
\hline $\begin{array}{l}\text { Boletín de la Oficina } \\
\text { Sanitaria } \\
\text { Panamericana (OSP) }\end{array}$ & La enseñanza de la ética en las escuelas de enfermería & 1963 \\
\hline $\begin{array}{l}\text { Boletín de la Oficina } \\
\text { Sanitaria } \\
\text { Panamericana (OSP) }\end{array}$ & La enseñanza de enfermeria & 1956 \\
\hline $\begin{array}{l}\text { Boletín de la Oficina } \\
\text { Sanitaria } \\
\text { Panamericana (OSP) }\end{array}$ & $\begin{array}{l}\text { Preparacion de auxiliares de enfermeras de salud } \\
\text { publica en Venezuela }\end{array}$ & 1956 \\
\hline $\begin{array}{l}\text { Boletín de la Oficina } \\
\text { Sanitaria } \\
\text { Panamericana (OSP) }\end{array}$ & $\begin{array}{l}\text { Integración de salud pública en el plan y programa } \\
\text { básico de estudios de enfermería: Resumen }\end{array}$ & 1951 \\
\hline Rev. cuba. Enferm & $\begin{array}{l}\text { La formación humanística de las enfermeras: una } \\
\text { necesidad insoslayable }\end{array}$ & 2013 \\
\hline Index enferm & $\begin{array}{l}\text { Desarrollo de los creditos de libre configuración en el } \\
\text { diseño curricular de la Escuela de Enfermería de la } \\
\text { Universidad de Huelva }\end{array}$ & 2004 \\
\hline Index enferm & La enseñanza de la historia de la enfermería en España & 2004 \\
\hline Rev. esp. salud pública & $\begin{array}{l}\text { Competencias y contenidos de Salud Pública del Grado } \\
\text { de Enfermería en las universidades españolas }\end{array}$ & 2018 \\
\hline Cult. Cuid & $\begin{array}{l}\text { O processo de criação do curso de especialização em } \\
\text { Enfermagem Obstétrica, modalidade de residência, na } \\
\text { rede municipal de saúde do Rio de Janeiro, Brasil }\end{array}$ & 2018 \\
\hline Cult. Cuid & $\begin{array}{l}\text { Enfoques históricos do ensino de Administração para a } \\
\text { formação identitária do enfermeiro }\end{array}$ & 2019 \\
\hline Cult. Cuid & História do ensino de História de Enfermagem no Brasil & 2019 \\
\hline Rev. bras. Enferm & O ensino de enfermagem em tempos de mudança & 2003 \\
\hline Rev. bras. Enferm & $\begin{array}{l}\text { Currículos de enfermagem do Brasil e as diretrizes: } \\
\text { novas perspectivas }\end{array}$ & 2003 \\
\hline $\begin{array}{l}\text { Esc. Anna Nery Rev. } \\
\text { Enferm }\end{array}$ & $\begin{array}{l}\text { Aspectos da formação profissional na Escola de } \\
\text { Enfermagem Alfredo Pinto (1943-1949) }\end{array}$ & 2006 \\
\hline $\begin{array}{l}\text { Hist. enferm., Rev. } \\
\text { eletronica }\end{array}$ & $\begin{array}{l}\text { Formação de auxiliares e técnicos de enfermagem em } \\
\text { Cascavel - Paraná: } 1980 \text { a } 2010\end{array}$ & 2015 \\
\hline $\begin{array}{l}\text { Biblioteca Oswaldo } \\
\text { Cruz }\end{array}$ & $\begin{array}{l}\text { A formação de auxiliares e técnicos de enfermagem nos } \\
\text { períodos colonial e pós-independência: um estudo dos } \\
\text { egressos da Escola Técnica Profissional de Saúde de } \\
\text { Luanda, Angola }\end{array}$ & 2011 \\
\hline
\end{tabular}

Fonte: Elaboração das autoras.

Essas bases de dados mostraram-se abrangentes quanto aos resultados apresentados e a seleção dos estudos não identificou tendência nas pesquisas.

As publicações selecionadas datam desde o ano 1952 até 2019 (Gráfico 1), sendo 1951 (1), 1956 (2), 1963 (1), 2003 (1), 2004 (2), 2006 (1), 2011 (1), 2013 (1), 2015 (1), 2018 (2), 2019 (2). 
Gráfico 1: Distribuição de publicações realizadas, por ano de publicação. São Paulo, 2020.

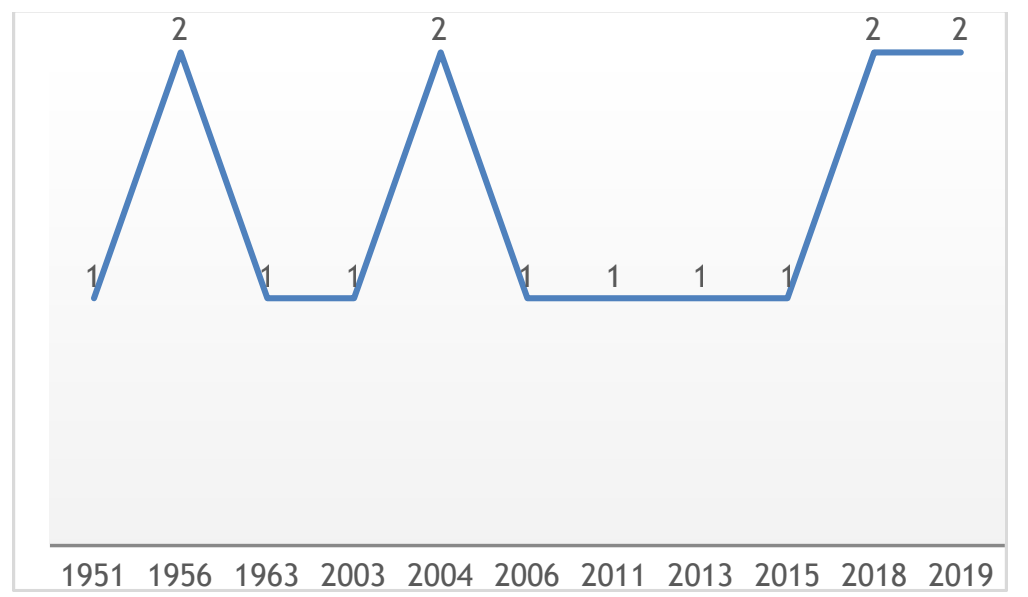

Fonte: Elaboração das autoras.

Esses resultados representam um comportamento da pesquisa em estudos do currículo de nível médio em enfermagem constante, porém, com poucos avanços.

Apesar de perceber que, durante as décadas de 1970 e 1980, a presença de estudos sobre a história do currículo educacional a culturas escolares e as reformas educativas não se expressam na educação de nível médio em enfermagem. De acordo com Viñao (1998: 47), o "planejamento do ambiente e do espaço é parte constitutiva e irrenunciável de um novo modo de considerar a criança, de tal maneira que os objetos e projeto educativo guardam, entre si, uma intima relação [...] com a utilização didática do espaço e de seu entorno".

\begin{abstract}
A instrumentalização concreta que um determinado sistema social faz da escola possuir íntima relação com o currículo escolar, o qual se apresenta como uma práxis, que organiza concepções e perspectivas educativas, e que, no entanto, não se esgota na parte explícita, mas só pode ser apreendido através do contexto em que se insere. Explicita-se, aqui, o outro fundamento no qual se apoia o trabalho, a partir do qual a escola é interpretada como sendo um lugar de cruzamento de processos sociais que permeiam seus limites físicos, o que a torna aberta a diversos movimentos sociais e culturais (Venturineli; Picarelli; Venturinell, 2017: 4).
\end{abstract}

É importante organizar os processos de profissionalização técnica, pois, de acordo com Viñao Frago (2004) é na memória que o processo de (re)construção do eu individual ou social recorda a "memória biográfica e a cultura, dos lugares da memória".

$\mathrm{Na}$ análise de conteúdo a respeito da história das disciplinas escolares, Viñao Frago (2006b) insiste em vincular os textos escolares e seus códigos de conteúdos formando valiosos modos de transmitir o ensino e sistematizando as sequências da aquisição dos novos conhecimentos. Este ordenamento fica evidente nos currículos escolares, em que as concepções pedagógicas apresentam as exigências formativas e as convenções rotineiras da formação do aluno.

Ressalta-se a importância em aprimorar os estudos a respeito do ensino de nível médio em enfermagem, pois, a formação profissional deste nível ainda ocupa grande parte do campo da educação em saúde e constitui mais da metade do corpo profissional em Enfermagem. Quanto aos autores das publicações podem citar Alcantara e Forjaz, Carter, Naranjo e Galarraga, Comité de Integración, Cano, Santos, Haro e Santos, Calatrava, Lana-Pérez, Caamanõ-Isorna, Baltasar-Bagué, Amezcua-Prieto, Vives-Cases, Davó-Blanes e o Grupo de la IV Reunión del Foro de Profesorado Universitario de Salud Pública en el Grado de Enfermería, Pereira, 
Mouta e Barbosa, Freitas, Takashi e Melo, Oguisso e Moreira, Germano, Santos, Bessa e Amorim, Feiber, Paiano, Conterno e Rodrigues e Tiago, todos autores apresentaram um trabalho na seleção deste estudo.

A procedência geografia e instituição de afiliação pode ser mais bem visualizada na Tabela 2. Apenas um artigo, publicado pelo Primer Seminario de Trabajo de Enfermería sobre Administración, Supervisión y Enseñanza de Enfermería, do Comité de Integración, em 1951, que indexado na base de dados PAHO, não foram possíveis identificar a procedência geográfica e sua filiação.

A veiculação de publicação desses estudos foram Boletín de la Oficina Sanitaria Panamericana (OSP) e a revista Cultura e Cuidados, com três artigos; as revistas Index Enfermagem e Revista Brasileira de Enfermagem, com dois artigos e; Revista de Enfermagem da Escola Anna Nery Revista Eletrônica História da Enfermagem, Biblioteca Oswaldo Cruz, Revista Especializada em Saúde Pública e Revista de Enfermagem de Cuba, com um artigo cada (Tabela 2).

Tabela 2: Relação das literaturas encontradas, segundo a procedências geográfica e a instituição afiliada. São Paulo, 2020.

\begin{tabular}{|c|c|c|}
\hline $\begin{array}{l}\text { Procedência } \\
\text { geográfica }\end{array}$ & Instituição/País de afiliação & $\begin{array}{c}\text { Tipo de } \\
\text { documento }\end{array}$ \\
\hline $\begin{array}{l}\text { América do Sul / } \\
\text { Venezuela }\end{array}$ & РAHO & Artigo \\
\hline América do Norte & PAHO & Artigo \\
\hline Cuba & Universidad de Ciencias Médicas de La Habana & Artigo \\
\hline Espanha & Universidad de Huelva & Artigo \\
\hline Espanha & Universidad de Murcia & Artigo \\
\hline Espanha & $\begin{array}{l}\text { Universidad de Oviedo, Universidad de Santiago de } \\
\text { Compostela, Universitat de Girona, Universidad de } \\
\text { Granada e Universidad de Alicante }\end{array}$ & Artigo \\
\hline Paraná & $\begin{array}{l}\text { Centro de Educação Profissional Pedro Boaretto Neto, } \\
\text { Universidade Estadual Oeste do Paraná, Universidade } \\
\text { Estadual do Oeste do Paraná e Universidade Federal do } \\
\text { Paraná/BR }\end{array}$ & Artigo \\
\hline Pernambuco & Universidade de Pernambuco & Artigo \\
\hline Rio de Janeiro & Escola Nacional de Saúde Pública Sérgio Arouca & Tese \\
\hline Rio de Janeiro & Escola de Enfermagem Alfredo Pinto & Artigo \\
\hline Rio de Janeiro & Universidade do Estado do Rio de Janeiro & Artigo \\
\hline $\begin{array}{l}\text { Rio Grande do } \\
\text { Norte }\end{array}$ & Universidade Federal do Rio Grande do Norte & Artigo \\
\hline São Paulo & Enfermagem - USP - Ribeirão Preto & Artigo \\
\hline São Paulo & Escola de Enfermagem da Universidade de São Paulo & Artigo \\
\hline São Paulo & Escola de Enfermagem da Universidade de São Paulo & Artigo \\
\hline
\end{tabular}

Fonte: Elaboração das autoras. 
A linguagem predominante dos artigos selecionados foi a espanhola, com oito artigos, seguida do português com oito artigos. Dentre as publicações todas foram artigos de periódicos e apenas uma era tese de dissertação, publicada em 2001, pela Escola Nacional de Saúde Pública Sérgio Arouca.

Os descritores mais utilizados foram Currículo, Educação, Educação em Enfermagem, Enfermagem, Escola de Enfermagem e História da Enfermagem.

\section{Considerações finais}

O estudo buscou identificar quais produções científicas descreveram e descreve estudos a respeito do currículo de ensino médio em enfermagem. Foi possível observar que os estudos sobre o ensino médio em enfermagem são constantes, porém, com pouca divulgação e avanço.

As publicações evidentes são encontradas nos anos de 2004, 2018 e 2019, concentrando os estudos nas instituições de língua espanhola e nas Escolas de Enfermagem da Universidade de São Paulo, tanto em São Paulo como em Ribeirão Preto.

Tal concentração demonstra carência no desenvolvimento desses estudos em outras universidades e escolas de enfermagem e, por isso, faz-se importante incentivar o avanço de estudos e pesquisas sobre a educação de nível médio em enfermagem, principalmente, destacando as mudanças curriculares ocorridas.

\section{Referências}

Afonso, S. R. \& Neves, V. R. (2018). Criação e implantação dos Cursos Técnicos em Enfermagem no Brasil. Temperamentvm, Granada, v. 14, e11722p. Disponível em: http://ciberindex.com/index.php/t/article/view/e11722p/e11722p. Acesso em: 05 out. 2020.

Silva, J. A. T. Á. (2017). O ensino profissional técnico de enfermagem e a formação para o SUS. 108 f. Dissertação (Mestrado em Enfermagem) - Escola de

Enfermagem, Universidade Federal de Minas Gerais, 2017. Disponível em: https:// repositorio.ufmg.br/bitstream/1843/ANDO-AUUP6L/1/

jo o andr tavares Ivares da silva.pdf. Acesso em: 05 out. 2020.

Venturineli, R.; Picarelli, S. S.; Venturinelli, R. (2017). A Reorganização do Espaço Escolar e suas Implicações Pedagógicas. Revista Acadêmica Integra/Ação, [S.I.], v. 1, n. 1, june. ISSN 2594-4878. Disponível em: http://www.fics.edu.br/index.php/ integraacao/article/view/542. Acesso em: 07 dec. 2020.

Viñao Frago, A. (1998). Currículo, espaço e subjetividade: a arquitetura como programa. Rio de Janeiro: DP\&A.

Viñao Frago, A. (2001). Do espaço escolar e da escola como lugar: propostas e questões. In: Viñao Frago, A.; Escolano, A. Currículo, espaço e subjetividade: a arquitetura como programa. $2^{a}$ ed. Rio de Janeiro: DP\&A. p. 60-139.

Viñao Frago, A. (2006a). Sistemas Educativos, Culturas Escolares e Reformas: continuidades y cambios. $2^{\mathrm{a}}$ ed., Madri: Ediciones Morata, S.L. 
Viñao Frago, A. (2006b). El libro de texto y las disciplinas escolares: una mirada a sus orígenes. In: Escolano, A. (ed.), Currículum editado y sociedad del conocimiento. Texto, multimedialidad y cultura de la escuela, Valencia, Tirant lo Blanch.

Viñao Frago, A. (2004). Relatos e relações autobiográficas de professores e mestres. In: Menezes, M. C. (org.). Educação, memória, história: possibilidades, leituras. São Paulo: Mercado de letras.

Wermelinger, M. C. M. W. et al. (2020). A formação do técnico em enfermagem: perfil de qualificação. Ciênc. saúde coletiva, Rio de Janeiro, v. 25, n. 1, p. 67-78, jan.

Disponível em: http://www.scielo.br/scielo.php? script=sci arttext\&pid=S1413-81232020000100067\&lng=en\&nrm=iso. Acesso em: 05 out. 2020. Epub Dec 20, 2019. https://doi.org/ 10.1590/1413-81232020251.27652019. 